\title{
CONSTRUÇÃO DE INDICADORES PARA RELATÓRIO DE SUSTENTABILIDADE DE UMA INSTITUIÇÃO DE ENSINO SUPERIOR
}

\section{CONSTRUCTION OF INDICATORS FOR SUSTAINABILITY REPORT OF AN INSTITUTION OF HIGHER EDUCATION}

\author{
Janaina Pasinato ${ }^{1}$ e Vandré B. Brião ${ }^{2}$ \\ ${ }^{1}$ Arquiteta Urbanista, Engenheira de Segurança do Trabalho, Especialista em Gestão de Organizações Públicas de Saúde e \\ Mestre em Engenharia/Faculdade de Engenharia e Arquitetura, Universidade de Passo Fundo (UPF). E-mail: \\ janainapasinato@bol.com.br \\ ${ }^{2}$ Engenheiro de Alimentos, Doutor em Engenharia Química e Professor da UPF; Universidade de Passo Fundo (UPF). E- \\ mail: vandre@upf.br
}

\section{RESUMO}

\begin{abstract}
Uma crescente preocupação global com o desempenho sustentável das organizações é atualmente observada, assim como das ações adotadas e da transparência frente aos seus indicadores. Neste intento o Relatório de Sustentabilidade (RS) da Global Reporting Initiative (GRI) mostra-se como o principal instrumento de comunicação do desempenho econômico, ambiental e social das organizações. A GRI, além das diretrizes para a elaboração de um RS, dispõe também de suplementos setoriais com indicadores particulares às atividades desenvolvidas por cada setor da economia, para a organização relatora que deseja melhor e mais amplamente comunicar seu desempenho frente à sustentabilidade. Alguns setores da economia, como o da educação, ainda não possuem estes indicadores específicos. Neste intuito, realizou-se um estudo de caso na Universidade de Passo Fundo, usando-se de roteiros de entrevistas, de observação direta e da análise de documentos, com o objetivo de avaliar os indicadores da GRI para o caso da Instituição de Ensino Superior e também de obter novos indicadores que suplementem a estrutura do RS da GRI, com a finalidade de se obter uma estrutura de indicadores característicos à Instituição de Ensino Superior estudada.
\end{abstract}

Palavras-chave: Indicadores de Sustentabilidade, Instituições de Ensino Superior, Global Reporting Initiative, Relatório de Sustentabilidade.

\begin{abstract}
A growing global concern with sustainable performance of organizations is currently observed, as well as the actions and transparency in relation to your indicators. In this purpose the sustainability report of the Global Reporting Initiative (GRI) shows up as the main instrument of communication of economic, environmental and social performance of organizations. The GRI, in addition to the guidelines for the preparation of a sustainability report, also offers sector supplements with particular indicators to the activities developed by each sector of the economy, to the reporting organization that wants better and more widely communicate their performance in sustainability. Some sectors of the economy, such as education, do not have these specific indicators. To this end, a case study at the University of Passo Fundo, using scripts, interviews, direct observation and analysis of documents, with the aim of assessing the GRI indicators for the case of Higher Education Institution and also to get new indicators to supplement the structure of the sustainability report of the GRI, with the purpose of obtaining a characteristic indicators to Higher Education Institution.
\end{abstract}

Keywords: Sustainability Indicators, Higher Education Institutions, Global Reporting Initiative, Sustainability Reporting.

\section{1 - INTRODUÇÃO}

Uma maior consciência da sociedade frente à degradação ambiental que decorria do processo de desenvolvimento foi presenciada ao final do século XX. Conferências internacionais, como a Rio 92, foram organizadas para discutir perspectivas, e as organizações começaram a aprimorar suas visões, antes puramente econômicas, para que seus processos de avaliação e divulgação de 
desempenho fossem ajustados estrategicamente em relação às imposições ambientais e as transformações sociais cada vez mais constantes (ROBINSON, 2000). A elaboração de um Relatório de Sustentabilidade (RS) se fez então uma prática consolidada (FDC, 2012) na avaliação e divulgação de desempenho em sustentabilidade das organizações.

A Global Reporting Initiative (GRI) dispõe de princípios e indicadores para uma elaboração padronizada de um RS, o que possibilita a comparabilidade, além estimular a demanda e a busca das informações pelas partes interessadas (GRI, 2012), uma vez que se vê ampliada a responsabilidade do negócio para além de suas próprias atividades (SAVITZ, 2007). Neste contexto, as Instituições de Ensino Superior (IES) se destacam como importantes veículos de disseminação da conscientização frente ao desenvolvimento sustentável e por seu papel multiplicador das ações vivenciadas (KRAEMER, 2004; SALGADO, 2006). De tal modo, Clark (2003) aponta para o novo conceito da universidade, o de modelo da sustentabilidade.

As diretrizes dadas pela GRI para elaboração de um RS podem ser utilizadas por toda e qualquer organização, independentemente de porte ou setor na economia (GRI, 2012), sendo também as mais utilizadas em âmbito mundial (ETHOS, 2012), porém em função das particularidades dadas às atividades de alguns setores, a própria GRI apresenta Suplementos Setoriais que objetivam um relato que siga o contexto, a realidade e a especificidade de cada setor (GRI, 2012).

Apesar das particularidades que o contexto educacional possui, como por exemplo, na questão da infraestrutura abordada por Tauchen (2007), ou ainda na questão do foco das IES em seu papel de agente de desenvolvimento social, como descrito por Cassol (2006) e Kraemer (2004), o setor de educação atualmente não possui um Suplemento Setorial com indicadores específicos, apresentando a necessidade do desenvolvimento de um instrumento alinhado a este contexto, ou seja, uma estrutura de indicadores que propicie uma elaboração simplificada e abrangente de um Relatório de Sustentabilidade para as IES.

A Universidade de Passo Fundo (UPF) divulga anualmente o Balanço Social e Demonstrativo de Informações de Natureza Social e Ambiental, mantém diversas atividades relacionadas à sustentabilidade (grupos, projetos, programas e campanhas), todavia, mesmo comprometida com a questão, ainda não possui um Relatório de Sustentabilidade e demostra separação na gestão das três dimensões da sustentabilidade, conforme evidenciada pela divulgação isolada de seus relatórios, e necessita de uma estrutura capaz de divulgar a sustentabilidade na universidade.

Mediante tais arguições, a pesquisa propõe-se a responder a seguinte questão:

Como uma IES comunitária pode melhor demonstrar seu desempenho econômico, ambiental, social através de indicadores específicos que suplementem o Relatório de Sustentabilidade baseado nas diretrizes da GRI?

\section{2 - RELATÓRIO DE SUSTENTABILIDADE: DEFINIÇÕES E APLICAÇÕES}

A partir da década de 60 a sociedade amplia sua visão sobre o desenvolvimento global, uma vez que inicia uma reflexão sistemática sobre sua influência neste processo, e percebe a necessidade de um desenvolvimento sustentável (VAN BELLEN, 2002) que, de acordo com Dyllick e Hockerts (2002), se deu justamente por levar ao século XXI a promessa de evolução social em um mundo mais justo e mais rico.

De acordo com o Relatório de Brundland, elaborado pela Comissão Mundial sobre Meio Ambiente e Desenvolvimento (CMMAD) em 1987, isso só é possível quando "A humanidade é capaz de tornar o desenvolvimento sustentável, de garantir que ela atenda as necessidades do presente sem comprometer a capacidade de as gerações futuras atenderem também às suas" (CMMAD, 1991, p. 9). 
Desde então o conceito passou a ser discutido em seu significado e as medidas necessárias para alcançá-lo. Baseado neste, Cordani (1995) discorre que o desenvolvimento sustentável "[...] pretende alcançar uma situação ideal de justiça social, para a humanidade, na qual o desenvolvimento socioeconômico, em bases equitativas, estaria em harmonia com os sistemas de suporte da vida na Terra. [...]" (CORDANI, 1995, p.14).

De acordo com Van Bellen (2002), não há uma concordância entre os estudiosos na definição do conceito de desenvolvimento sustentável, consequentemente, não há também como medir a sustentabilidade e a interação entre as diferentes dimensões. Na ampla discussão e uso do conceito, diversos autores colocam-no sobre pilares distintos, de acordo com suas teorias.

Mesmo diante de tantas teorias, apontando diferentes dimensões, de acordo com Harris (2000) tem sido geralmente reconhecidas três dimensões (triple bottom line ${ }^{1}$ ) envolvendo o desenvolvimento sustentável (Figura 1):

a) Econômica: Um sistema economicamente sustentável deve ser capaz de produzir bens e serviços de forma contínua, manter os níveis de governo e dívida externa gerenciável, e evitar extremos desequilíbrios setoriais que tragam danos agrícolas à produção industrial.

b) Ambiental: Um sistema ambientalmente sustentável deve manter uma estável base de recursos, evitando sobre-exploração dos sistemas de recursos renováveis ou funções ambientais, e esgotando os recursos não renováveis apenas na medida em que haja investimento em substitutos adequados. Isto inclui a manutenção da biodiversidade, estabilidade atmosférica, e outras funções do ecossistema, normalmente, não classificados como recursos econômicos.

c) Social: Um sistema socialmente sustentável deve alcançar equidade distributiva, adequada prestação de serviços sociais, incluindo saúde e educação, igualdade de gênero e políticas de responsabilidade participativa.

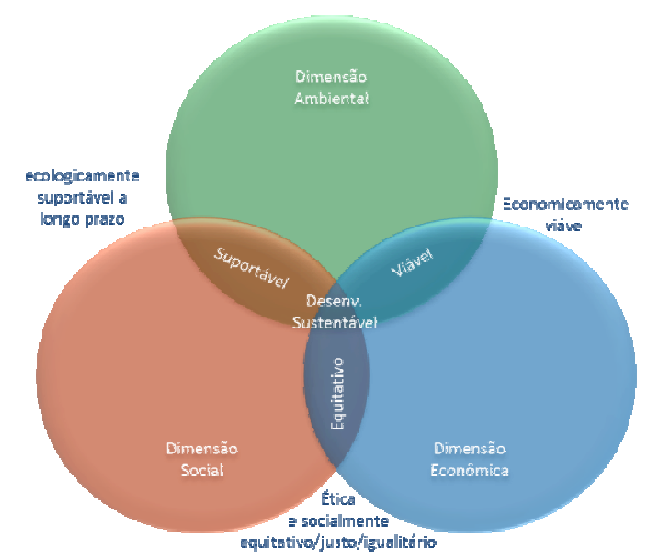

Fonte: Elaborado pela Autora a partir de USNW (2012.).

Figura 1 - Representação das várias componentes do desenvolvimento sustentável

A atividade econômica, o meio ambiente e o bem-estar global da sociedade formam o tripé básico no qual se apoia a ideia de desenvolvimento sustentável e só pode ser alcançado se os três componentes evoluírem de forma harmoniosa (BCSD, 2007, p. 3), onde a resultante está nas questões ecologicamente corretas, economicamente viáveis e socialmente justas, que é amplamente usada pelas organizações, inclusive como modelo de sustentabilidade para seus negócios (ELKINGTON, 2011).

\footnotetext{
${ }^{1}$ Triple bottom line é um termo em inglês que significa tripé básico ou três pilares: "People", pessoas; "Planet", planeta e "Profit", lucro; referindo-se a dimensão social, ambiental e econômica, componentes básicos equitativos para o desenvolvimento sustentável. (BCSD, 2007, p.3). O termo é advindo do conceito criado nos anos 90 por John Elkington.
} 
Um Relatório de Sustentabilidade é o único capaz de comunicar de forma integrada as três dimensões, dando maior transparência e expandindo o diálogo das empresas com a sociedade e demais stakeholders ${ }^{2}$ (ETHOS, 2007).

O relato de sustentabilidade se dá pela prática de medir, divulgar e prestar contas para os interessados internos e externos do desempenho organizacional, de governança e dos impactos econômicos, ambientais e sociais visando o desenvolvimento sustentável. Esse documento deve oferecer uma descrição equilibrada e sensata das informações relatadas, divulgando resultados obtidos dentro de um período de tempo, no contexto dos compromissos, da estratégia e da forma de gestão da organização; incluindo informações tanto positivas como negativas (GRI, 2012).

\subsection{Global Reporting Initiative (GRI)}

A Global Reporting Initiative (GRI) é uma Organização Não-Governamental (ONG) internacional composta por uma rede multi stakeholders (rede diversificada em público de interesse), cuja missão é desenvolver e disseminar globalmente diretrizes para a elaboração de relatórios de sustentabilidade no mundo todo. Foi fundada em 1997 como a iniciativa da Coalition for Environmentally Responsible Economies (CERES), uma ONG americana composta por organizações ambientais de trabalhadores, religiosos, profissionais de investimentos socialmente responsáveis e por investidores institucionais, em parceria com o United Nations Environment Program (UNEP) chamada no Brasil como Programa das Nações Unidas para o Meio Ambiente (PNUMA) (GRI, 2012).

Em 2002 a GRI mudou-se para Amsterdã, na Holanda, onde se encontra atualmente sediada. Ela conta também com os representantes regionais, os chamados Pontos Focais (Focal Points) nos países da Austrália, Brasil, China, Índia e Estados Unidos, além de uma rede mundial de 30.000 pessoas (GRI, 2012).

Desde o início, a GRI, por meio de aprendizagem contínua, pesquisa e comentários públicos em ciclos regulares - reunindo centenas de parceiros, num processo voluntário, multi stakeholders e consensual - tem focado no desenvolvimento de um padrão de relatório que englobe a abordagem dos aspectos relacionados à sustentabilidade econômica, social e ambiental das organizações. Seu objetivo é elevar as práticas de elaboração e divulgação de relatórios de sustentabilidade e atribuir a estes a mesma utilidade, seriedade e qualidade dos relatórios e balanços financeiros, conferindo-lhes assim status de documento (GRI, 2012).

O Brasil foi o primeiro país onde a GRI estabeleceu um Ponto Focal e este está alocado em São Paulo, sediado no Instituto Brasileiro de Governança Corporativa (IBGC), tendo sido hospedado anteriormente pelo Instituto Ethos. O Ponto Focal trabalha diretamente com instituições parceiras em todo o país. Cultiva e agrega uma rede em expansão de organizações relatoras, usuários de relatórios e patrocinadores da GRI.

De acordo com a GRI (2012), dentre as razões que as organizações têm para a divulgação de um RS podem-se destacar:
a) Aumento a compreensão sobre os riscos e oportunidades que enfrentam;
b) Melhora da reputação e a fidelidade à marca;
c) Dar compreensão aos interessados do desempenho e impactos de sustentabilidade.
d) Enfatizar a relação entre desempenho organizacional financeiro e não financeiro;
e) Influenciar na estratégia e politica de gestão em longo prazo e planos de negócios;

\footnotetext{
2 Stakeholder: O termo em inglês vem de "Stake" - interesse, participação, risco; "Holder" - aquele que possui. É qualquer pessoa, colaborador, funcionário, cliente, consumidor, comunidade, planejador, investidores e acionistas, fornecedor, concorrentes, governo e demais instituições que direta ou indiretamente tenham interesses, sejam afetados por um projeto, interfiram nas atividades gerenciais e nos resultado de uma organização.
} 
f) Servir como padrão de referência (Benchmarking) e avaliação de desempenho com respeito às leis, normas, códigos, padrões de desempenho e iniciativas voluntárias;

g) Demonstrar como a organização influencia e é influenciada pelas expectativas relativas ao desenvolvimento sustentável;

h) Comparar o desempenho organizacional interno e entre outras organizações;

i) Conformidade com normas nacionais ou requisitos da bolsa de valores.

Segundo o Instituto Ethos (2012), ele pode ser definido como um documento anual produzido voluntariamente pela empresa após um esforço de "auditoria interna" para mapear seu grau de sustentabilidade. Essa "auditoria" busca entender a gestão da ação e avaliá-la, conforme critérios ambientais, sociais, econômicos e inclusive de governança. Além disso, mostra-se uma vantajosa ferramenta operacional, como plataforma orientadora para as mudanças, possibilitando estabelecer objetivos e metas, transformações operacionais, controle de externalidades, comunicar impactos positivos e negativos, e reunir informações que podem influenciar na política, na estratégia e nas operações da organização continuamente (BINKOWSKI, 2008; GRI, 2012; LEGITIMUS, 2012).

Neste intento, a GRI lança "Diretrizes para Elaboração de um Relatório de Sustentabilidade", a fim de obter um relato equilibrado e padronizado dos aspectos de sustentabilidade tratados pelas organizações (GRI, 2012). A Estrutura do RS da GRI consiste em diretrizes de elaboração, dentre as quais estão orientações e princípios para o relato, e o conteúdo do relatório, conforme Figura 2.

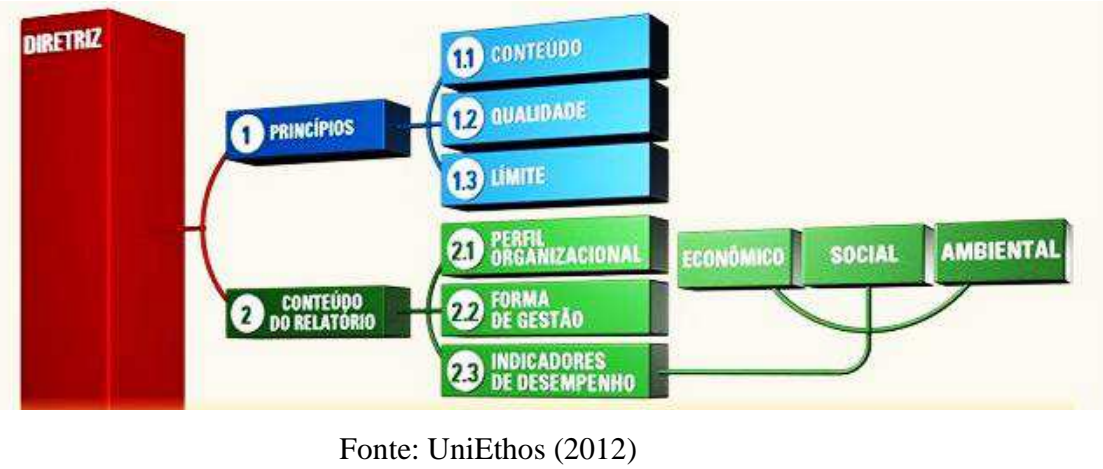

Figura 2 - Visão geral das diretrizes da GRI

Tal estrutura possui dois objetivos, um acerca de como relatar e a outra sobre o que se relatar, conforme mostra a Figura 3.

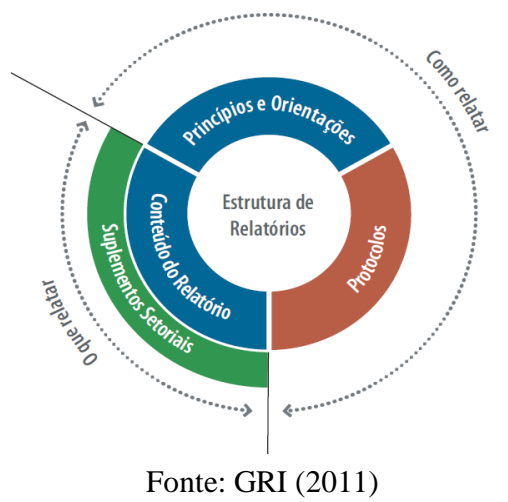

Figura 3 - A estrutura do RS da GRI

A elaboração do relatório GRI é baseada em princípios essenciais que visam o equilíbrio entre os itens econômicos, sociais e ambientais, além de proporcionar a comparabilidade temporal, garantir credibilidade e permear o colóquio entre as partes interessadas (GRI, 2012). 
O RS da GRI passa por duas fases, onde a primeira reúne os princípios da definição e orientações (escopo, qualidade e limite do relatório). Na segunda estão elementos estruturantes do relatório, o conteúdo propriamente dito, como a apresentação do perfil da empresa, forma de gestão e os indicadores (econômicos, ambientais, sociais).

Os indicadores de desempenho da versão G 3.1 estão divididos entre 3 (três) dimensões, totalizando 37 (trinta e sete) aspectos trabalhados, com 55 (cinquenta e cinco) indicadores essenciais e 29 (vinte e nove) adicionais, totalizando 84 (oitenta e quatro) indicadores (Quadro1).

Quadro 1 - Panorama dos indicadores da G3.1 da GRI

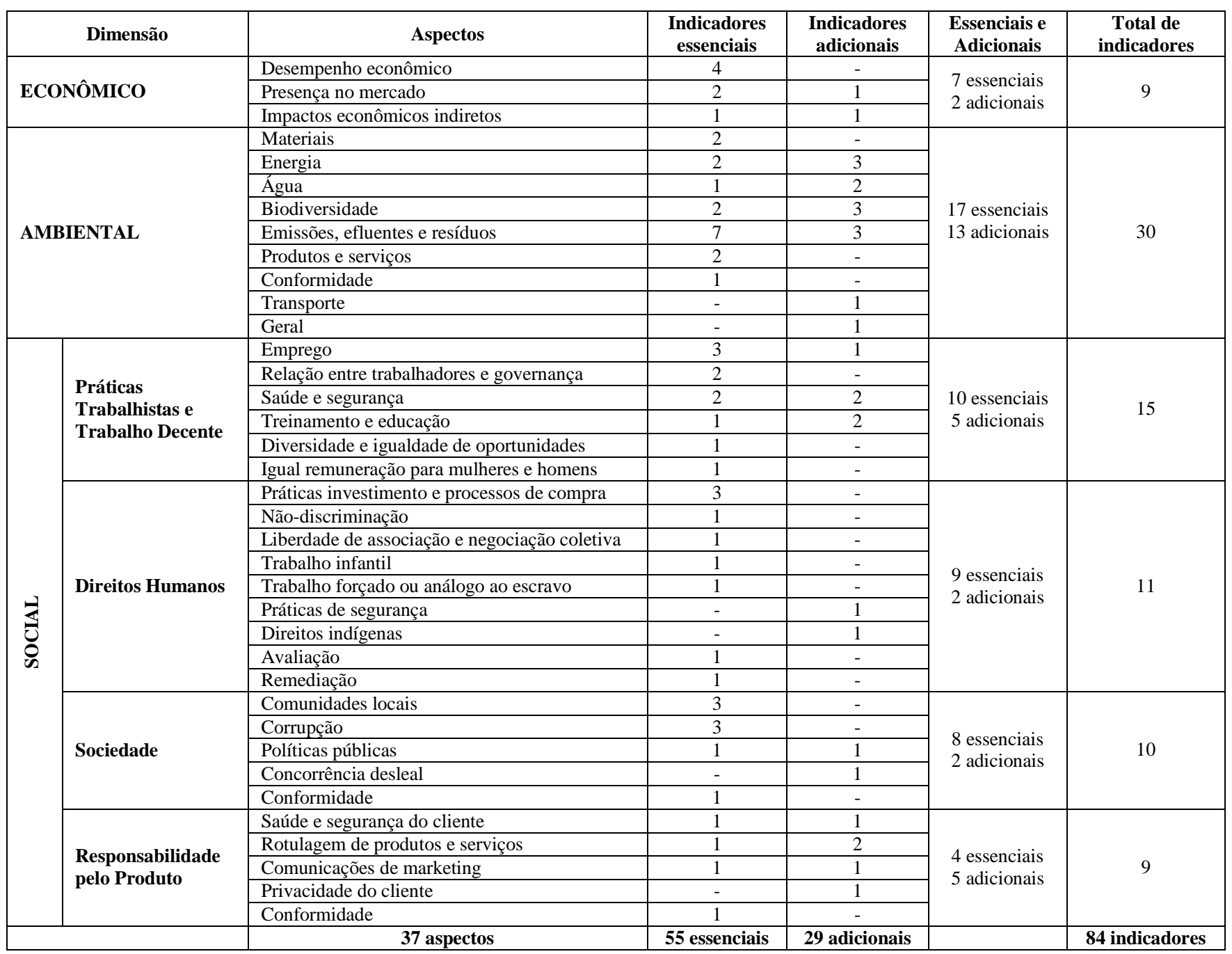

Fonte: Elaborado pela Autora a partir da GRI versão G3.1 (2011)

As Diretrizes da GRI para elaboração do RS podem ser utilizadas por toda e qualquer organização, independente de seu setor na economia, porém para adaptar à realidade das organizações, a própria GRI dispõe de Suplementos Setoriais que objetivam um relato que possa seguir o contexto, a realidade e a especificidade de cada setor (GRI, 2012). A GRI dispõe suplementos para os setores de Eletricidade, Serviços financeiros, Mineração e Metais, ONGs, Processamento de alimentos, Construção \& Imobiliário, Operadores de Aeroportos, Organizadores de evento, Mídia e Petróleo \& Gás (GRI, 2012). O setor de educação ainda não possui um Suplemento Setorial específico. 


\section{3 - INSTITUIÇÕES DE ENSINO SUPERIOR E A SUSTENTABILIDADE}

As IES atuam como líderes na criação das mudanças sociais, aprimorando o potencial humano em administrar os recursos disponíveis (CMMAD, 1991, p. 12 e 13) através dos vários segmentos das universidades, como o ensino, pesquisa, extensão, operação, design, construções e vida universitária. Aumentam a consciência, o conhecimento e as habilidades, ao passo que vão preparar a maioria dos profissionais que vão desempenhar funções de liderança, gerenciamento e ensino no futuro. E mais do que contribuir para o ensino, as universidades devem desenvolver em seus campi as ações que doutrinam (ULSF, 1999; WEENEN, 2000; WRIGHT, 2005).

As IES preparam a comunidade acadêmica, para posteriormente, atuarem na sociedade como agente influenciador e transformador (UPF, 2012). Segundo Salgado (2006), as IES se mostram importantes veículos de disseminação da conscientização necessária frente ao desenvolvimento sustentável. São "instituições responsáveis pela produção e socialização do conhecimento e a formação de recursos humanos, têm um papel importante: dar o exemplo (produzir, socializar e formar respeitando o meio ambiente)" (CONTO, 2010. p.9).

A universidade é um microcosmo de uma comunidade maior, portanto, a maneira como desempenha suas atividades é uma forma de demonstrar como atingir a responsabilidade ambiental e reforçar as atitudes que são esperadas de toda comunidade (CORTESE, 2003).

Nicolades (2006) destaca a universidade como "sociedade em miniatura" de forma que deve estar comprometida com a responsabilidade econômica, ambiental e social. Explana que, além da questão ética e justificativa do que ensina em sala de aula, também a inclusão da sustentabilidade pode gerar economias e contribuir para a imagem pública da instituição, mostrando a importância de aplicar nas operações aquilo que ensina sobre sustentabilidade. Analisando seu porte e instalações, os campi universitários "podem ser comparados com pequenos núcleos urbanos, pois abrangem inúmeras atividades no interior do campus" (TAUCHEN, 2007. p. 13) e quanto mais cursos e atividades, maior a demanda por funções, o que necessita de um planejamento detalhado dos campi universitários com relação à mobilidade, transporte, gerenciamento de recursos e resíduos, entre outros.

A IES diferenciando-se das demais organizações apenas por ter um campus como infraestrutura, ensino como matéria prima, conhecimento como produto e alunos como clientes. E, como as demais, mantem gestão de setores, para assegurar bom desempenho, qualidade e resultados (BLEWITT, 2001). Porém, para a inclusão da sustentabilidade, algumas barreiras são encontradas, dentre estas Evangelinos et al. (2009) destacam a necessidade de conhecimento sobre o assunto, o nível de participação e cooperação dos membros da comunidade acadêmica, a existência de limitações na estrutura organizacional das IES e barreiras financeiras. Velazquez et al. (2005) citam também a falta de interesse e envolvimento, relacionada à falta de conhecimento, que dificulta a inclusão da sustentabilidade. Além disso, os autores também destacam a estrutura conservativa das universidades, impedindo a existência de iniciativas sustentáveis.

Para Savitz (2007, p.144), "muitas questões de sustentabilidade são altamente específicas em relação aos diferentes setores" e destas questões surge a necessidade de indicadores que medirão a sustentabilidade nas IES e ditarão a necessidade de complementações específicas e adaptações para avaliar a efetividade e o desempenho nas práticas desenvolvidas. (VELAZQUEZ et al., 2006).

\section{4 - METODOLOGIA}

Na fase 1, foi feita a seleção do objeto de estudo. Os Conjuntos de protocolos da GRI foram selecionados por os mais amplamente usados mundialmente. Após foi selecionada a unidade de análise, neste caso, a Universidade de Passo Fundo (UPF), localizada na cidade de Passo Fundo, ao norte do estado do Rio Grande do Sul, a $300 \mathrm{~km}$ da capital do estado, Porto Alegre, no Brasil. A 
seleção deste caso se deu em função de suas características, sua abrangência, seu caráter comunitário e pelo acesso facilitado às informações. Sua mantenedora a Fundação Universidade de Passo Fundo (FUPF) que foi fundada em 28 de junho de 1967, é uma entidade administrativa e financeiramente autônoma, privada, com personalidade jurídica nos termos da lei e duração indeterminada. Tem sede localizada junto ao campus I da UPF (UPF, 2012).

$\mathrm{Na}$ fase 2, foi elaborado um Protocolo para o Estudo de Caso o qual, de acordo com Gummesson (2007), confere alta confiabilidade ao estudo por garantir replicabilidade, objetivando garantir que outros pesquisadores possam chegar aos mesmos resultados (YIN, 2001). O protocolo é constituído de um conjunto de informações, métodos e procedimentos suficientes para se replicar o estudo, ou aplicá-lo em outro caso que mantém características semelhantes ao estudo de caso original (MARTINS, 2008). Foram elaborados roteiros de entrevista e um roteiro de observação direta para investigar se os indicadores da GRI deveriam ser mantidos, excluídos ou alterados. Também se deveria haver a inclusão de um novo indicador na estrutura proposta.

Na fase 3 foram coletados, analisados e interpretados os dados para a construção da estrutura de indicadores para o RS da IES estudada. Após a interpretação dos dados foram apontados os indicadores da GRI que foram mantidos, sofreram alterações ou foram excluídos. Também foram acrescidos indicadores novos para suplementar e melhor relatar a sustentabilidade da IES. Na Figura 4 estão descritas as fases e etapas realizadas durante a pesquisa.

\begin{tabular}{|c|c|c|c|}
\hline \multirow[t]{2}{*}{ 手 } & 1. Seleção do objeto de estudo & \multirow{2}{*}{$\begin{array}{l}\Rightarrow \\
\Rightarrow\end{array}$} & $\begin{array}{l}\text { 1.1 Conjunto de Protocolos de Indicadores do RS da GRI: } \\
\text { 1.1.1 Econômico } \\
\text { 1.1.2 Ambiental } \\
\text { 1.1.3 Social } \\
\text { 1.1.3.1 Práticas Trabalhistas e Trabalho Decente } \\
\text { 1.1.3.2 Direitos Humanos } \\
\text { 1.1.3.3 Sociedade } \\
\text { 1.1.3.4 Responsabilidade pelo Produto }\end{array}$ \\
\hline & 2. Seleção da unidade de análise & & 2.1 Universidade de Passo Fundo \\
\hline \multirow{3}{*}{ 窟 } & $t$ & & \\
\hline & $\begin{array}{l}\text { 1. Elaboração do Protocolo de Estudo de } \\
\text { caso (Yin, 2001). }\end{array}$ & $\Rightarrow$ & $\begin{array}{l}\text { 1.1 Visão global do projeto } \\
\text { 1.2 Procedimentos de campo } \\
\text { 1.3 Determinação das questões do estudo } \\
\text { 1.4 Guia para a elaboração do relatório }\end{array}$ \\
\hline & $\begin{array}{l}\text { 2. Construção dos instrumentos da } \\
\text { pesquisa }\end{array}$ & $\Rightarrow$ & $\begin{array}{l}\text { 2.1 Elaboração dos Roteiros de Entrevista } \\
\text { 2.1.1 Roteiro de entrevista ao gestor econômico } \\
\text { 2.1.2 Roteiro de entrevista ao gestor ambiental } \\
\text { 2.1.3 Roteiro de entrevista ao gestor social } \\
\text { 2.2 Elaboração do Roteiro de Observação Direta }\end{array}$ \\
\hline \multicolumn{4}{|c|}{ 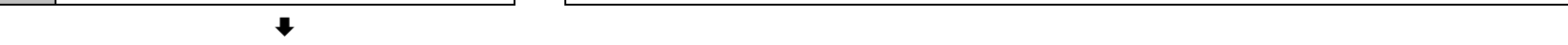 } \\
\hline \multirow{4}{*}{ 窟 } & 1 Coleta de dados & \multirow[t]{2}{*}{$\Rightarrow$} & $\begin{array}{l}\text { 1.1 Coleta de dados através das entrevistas aos gestores } \\
1.2 \text { Coleta de dados através de observação direta } \\
1.3 \text { Coleta de dados por documentos }\end{array}$ \\
\hline & 2 Análise e Tratamento de dados & & $\begin{array}{l}\text { 2.1 Análise individual das entrevistas, organização das informações e elaboração de relatórios } \\
\text { 2.2 Análise individual das observações diretas, organização das informaçôes e elaboração de } \\
\text { relatório } \\
\text { 2.3 Análise individual de documentos e criação de arquivo de notas }\end{array}$ \\
\hline & 3 Interpretação dos dados & \multirow[t]{2}{*}{$\Rightarrow$} & $\begin{array}{l}\text { 3.1 Triangulação dos dados (cruzamento dos dados obtidos pelas entrevistas aos gestores, } \\
\text { pelas observação direta e dos documentos) } \\
\text { 3.2 Apontamento das interferências em cada indicador individualmente }\end{array}$ \\
\hline & $\begin{array}{l}4 \text { Construção da estrutura de indicadores } \\
\text { para o RS da IES estudada. }\end{array}$ & & $\begin{array}{l}\text { 4.1 Apontamento dos indicadores da GRI que foram mantidos, alterados ou excluídos. } \\
\text { 4.2 Apontamento dos indicadores novos que foram suplementados. }\end{array}$ \\
\hline
\end{tabular}

Fonte: Elaborado pela autora, 2012.

Figura 4 - Fluxograma das atividades realizadas durante a pesquisa 


\section{5 - ANÁLISE, INTERPRETAÇÃO E APRESENTAÇÃO DE DADOS}

A análise e interpretação dos dados ocorreram através da triangulação dos dados, a qual foi obtida com a elaboração de uma planilha eletrônica contendo 5 (cinco) seções (dos indicadores originais da GRI, dos resultados das entrevistas, dos resultados das observações diretas, dos resultados dos documentos e do resultado final). Após a inserção das informações em cada seção, cada indicador passou individualmente pela interpretação dos dados, resultando na manutenção, alteração ou exclusão do indicador ou ainda na inclusão de novos indicadores na seção do resultado final.

Como resultados obtidos, do total de 9 (nove) indicadores de desempenho econômico da GRI, 3 (três) se mantiveram inalterados, permanecendo como são descritos pela GRI e 6 (seis) sofreram alteração, mostrando que $33 \%$ foram mantidos e $67 \%$ dos indicadores sofreram alterações.

Do total de 30 (trinta) indicadores do desempenho ambiental da GRI, 26 (vinte e seis) foram mantidos e 4 (quatro) sofreram alteração, mostrando que obteve-se a manutenção de $87 \%$ dos indicadores e a alteração de $13 \%$.

Dos 15 (quinze) indicadores de desempenho social da GRI, relacionados às Práticas Trabalhistas e Trabalho Decente, 9 (nove) foram mantidos (60\% de manutenção dos indicadores da GRI); 5 (cinco) foram alterados (33\%) e 1 (um) foi excluído, representando 7\%.

De um total de 11 (onze) indicadores de desempenho social da GRI, relacionados aos Direitos Humanos, 8 (oito) se mantiveram inalterados, representando $73 \%$ de manutenção dos indicadores da GRI; 3 (três) foram alterados, representando $27 \%$ dos indicadores.

De um total de 10 (dez) indicadores de desempenho social da GRI, relacionados a Sociedade , 6 (seis) foram mantidos, representando 60\%; 4 (quatro) sofreram alteração, mostrando $40 \%$ de adequação às atividades da IES.

Dos 9 (nove) indicadores de desempenho social da GRI, relacionados a responsabilidade do Produto, 7 (sete) se mantiveram inalterados, representando $78 \%$ do total, o que mostra boa compatibilidade com o intento do relato da IES. Dos outros 2 (dois), um foi alterado e o outro excluído, representando para cada $11 \%$ do total.

Analisando a estrutura de indicadores que se obteve, pode-se observar a forte aderência à estrutura original da GRI, o que a evidencia como um modelo unânime entre organizações de diversas naturezas. Os aspectos de cada dimensão também se mantiveram análogos aos da GRI. Contudo, as propostas de alterações e adição de novos indicadores evidenciaram a necessidade de ajustes e aporte do modelo da GRI para que se obtenha um relato mais característico ao perfil da IES e capazes de ampliar a transparência no relato do desempenho de sustentabilidade.

Neste sentido pode-se apresentar o quadro com os indicadores resultantes da triangulação dos resultados que foram obtidos através das entrevistas, das observações diretas e dos apontamentos nos documentos analisados (Quadro 2, 3 e 4). Como forma de identificação rápida, estão em negrito as alterações e/ou acrescimos aos indicadores da GRI, assim como os novos indicadores suplementados que também estão indicados com o código iniciado por UPF e seguido do numero de ordem. Os demais indicadores da GRI que não aparessem neste quadro se mantiveram da mesma forma como são descritos nas Diretrizes para Elaboração de um Relatório de Sustentabilidade da GRI (2012).

Quadro 2 -Indicadores de desempenho econômico para Relatório de Sustentabilidade da UPF

\section{INDICADORES DE DESEMPENHO ECONÔMICO}

\footnotetext{
\begin{tabular}{|l|l|}
\hline Classe & Indicador \\
\hline
\end{tabular}
}

Aspecto: Desempenho econômico

ESS $\quad$ EC1 Valor econômico direto gerado, investido e distribuído, incluindo mensalidades, receitas, custos operacionais, remuneração de empregados, doações e outros investimentos na comunidade, lucros acumulados e pagamentos para provedores de capital e governos.

ESS $\quad$ EC3 Cobertura das obrigações do plano de pensão de benefício definido e de contribuição definida que a organização oferece. 
ADI $[$ [UPF_EC10] Progressão, ao longo do tempo, da ajuda recebida do governo, por tipo e instância.

ADI [UPF_EC11] Taxa de crescimento no orçamento.

Aspecto: Presença no mercado

ESS $\quad$ EC5 Proporção entre salário mais alto, mais baixo e salário mínimo.

ESS $\quad$ EC6 Politicas e prática de gastos com fornecedores e proporção de fornecedores locais.

ESS $\quad$ EC7 Descrição dos procedimentos de contratação.

Aspecto: Impactos econômicos indiretos

ESS $\quad$ EC9 Identificação e descrição de impactos econômicos indiretos negativos e positivos significativos, incluindo a extensão dos impactos.

Fonte: Elaborado pela Autora a partir da GRI versão G3.1 (2011)

Quadro 3 - Estrutura de indicadores de desempenho ambiental para Relatório de Sustentabilidade da UPF INDICADORES DE DESEMPENHO AMBIENTAL

Classe Indicador

Aspecto 2: Energia

ADI [UPF_EN31] Progressão na substituição da energia não renovável pela energia renovável.

Aspecto 3: Água

ADI [UPF_EN32] Progressão ao longo do tempo da adesão ao aproveitamento de água da chuva, de reuso ou para reciclagem.

Aspecto 4: Biodiversidade

ESS $\quad$ EN14 Estratégias, medidas em vigor e planos futuros para a gestão de impactos na biodiversidade.

Aspecto 5: Emissões, efluentes e resíduos.

ESS $\quad$ EN18 Iniciativas para reduzir as emissões de gases de efeito estufa e as reduções obtidas.

ADI [UPF_EN33] Estratégias, medidas e planos futuros para a gestão de impactos das emissões, efluentes e resíduos.

Aspecto 6: Produtos e serviços

ESS EN27 Percentual de produtos e embalagens recuperados após seu uso nos serviços, por categoria de produto.

Aspecto 7: Conformidade

ADI [UPF_EN34] Estratégias, medidas e planos de gestão da conformidade com leis e regulamentos ambientais.

Aspecto 8: Transporte

ADI $\quad$ EN29 Impactos ambientais significativos do transporte de produtos, bens e materiais utilizados nas operações da organização, bem como do ADI transporte de trabalhadores e usuário dos serviços (alunos) e medidas tomadas.

ADI [UPF_EN35] Iniciativas no processo de substituição do transporte automotivo individual (maior impacto) para o transporte automotivo ADI $\begin{aligned} & \text { coletivo (menor impacto). } \\ & \text { col }\end{aligned}$

ADI [UPF_EN36] Iniciativas no processo de substituição de transporte automotivo pelo transporte alternativo (caminhada, bicicleta, por exemplo)

ADI [UPF_EN37] Adesão a programas e campanhas que visam diminuir impacto do transporte.

Aspecto 9: Geral

ADI [UPF_EN38] Iniciativas de treinamento e conscientização dos funcionários e comunidade acadêmica em ações ambientais, por temas.

Fonte: Elaborado pela Autora a partir da GRI versão G3.1 (2011)

Quadro 4 - Estrutura de indicadores de desempenho social para Relatório de Sustentabilidade da UPF

\begin{tabular}{|c|l|}
\hline \multicolumn{2}{|c|}{ INDICADORES DE DESEMPENHO SOCIAL } \\
\hline \multicolumn{2}{|c|}{ PRÁTICAS TRABALHISTAS E TRABALHO DECENTE } \\
\hline Classe & Indicador \\
\hline Aspecto: 1 Emprego \\
\hline ESS & $\begin{array}{l}\text { LA3 Benefícios oferecidos a empregados de tempo integral que não são oferecidos a empregados temporários ou em regime de meio período, } \\
\text { discriminados pelas principais operações. }\end{array}$ \\
\hline ESS & [UPF_LA16] Retorno ao trabalho e taxas de retenção após afastamento por doença e acidente de trabalho. \\
\hline Aspecto 3: Saúde e segurança \\
\hline ESS & LA7 Descrição e taxas de acidentes, lesões, doenças ocupacionais, dias perdidos, absenteísmo e óbitos relacionados ao trabalho, por unidade. \\
\hline ADI & [UPF_LA17] Adesão a campanhas e programas nacionais que visam diminuir acidente e doenças ocupacionais. \\
\hline ADI & [UPF_LA18] Média de horas de treinamento por ano, por assunto e taxas de participação. \\
\hline Aspecto 4: Treinamento e educação \\
\hline ESS & LA10 Média de horas ofertadas e taxa de participação em treinamento por ano, por funcionário, discriminadas por categoria funcional \\
\hline ESS & $\begin{array}{l}\text { LA11 Programas para gestão de competências e aprendizagem contínua que apoiam a continuidade da empregabilidade dos funcionários e para } \\
\text { gerenciar o fim da carreira. }\end{array}$ \\
\hline
\end{tabular}


ESS $\quad$ LA12 Percentual de empregados que recebem regularmente análises de desempenho e de desenvolvimento de carreira.

Aspecto 5: Diversidade e igualdade de oportunidades

ADI [UPF_LA19] Percentual de atendimento às cotas de inclusão (Pessoas com deficiências - PCDs, raciais e outros). DIREITOS HUMANOS

Classe Indicador

Aspecto 1: Práticas de investimentos e de processos de compra

ESS $\quad$ HR3 Percentual de participação e total de horas de treinamento para empregados em políticas e procedimentos relativos a aspectos de direitos ESS humanos relevantes para as operações, por unidade.

Aspecto 2: Não-discriminação

ESS $[$ [UPF_HR12] Descrição das politicas e práticas adotadas contra atos de discriminação.

Aspecto 6: Práticas de segurança

ESS $\quad$ HR8 Percentual do pessoal de segurança submetido a treinamento nas políticas ou procedimentos da organização relativos a aspectos de direitos humanos que sejam relevantes às operações.

ESS [UPF_HR13] Temas abordados e percentual de participação em treinamentos que o pessoal de segurança recebe visando atender aos direitos humanos

Aspecto 8: Avaliação

ESS $\quad$ HR10 Percentual e número total de operações que tenham sido objeto de críticas de direitos humanos e/ou avaliações de impacto.

ADI [UPF_HR14] Numero de unidades avaliadas e treinadas no atendimento aos direitos humanos e temas abordados.

Aspecto 9: Remediação

ESS $\quad$ HR11 Descrição dos mecanismos de queixa formal e número de queixas relacionadas aos direitos humanos, por tipo de abordagem (arquivados, apurados e resolvidos), por tipo de caso.

Classe Indicador

Aspecto 1: Comunidades Locais

ESS $\quad$ SO1 Natureza, escopo e eficácia de programas e práticas adotadas para diagnosticar, avaliar e gerir os impactos, incluindo a entrada, operação e saída.

ESS SO9 Operações com significativos, potenciais ou reais, impactos negativos e positivos sobre as comunidades locais e a sua natureza.

ESS [UPF_SO11] Descrição dos impactos negativos e positivos significativos sobre as comunidades locais, por tipo de operação, e a abrangência territorial e proporção do impacto sofrido.

ADI [UPF_SO12] Descrição dos programas de extensão oferecidos pela IES e sua abrangência (territorial, social, cultural).

ADI [UPF_SO13] Descrição dos canais e níveis de participação das comunidades locais nas operações e programas de extensão oferecidos pela IES, por fases (planejamento, operação, verificação).

Aspecto 2: Corrupção

ESS $\quad$ SO2 Percentual e número total de unidades submetidas a avaliações de riscos relacionados à corrupção.

ESS SO3 Políticas e procedimentos anticorrupção da organização, seu processo de adoção e construção, e o percentual de empregados formados.

Aspecto 3: Políticas públicas

ADI [UPF_SO14] Posição, nível de consonância e articulação dos programas de extensão oferecidos pela IES quanto às políticas públicas e participação na construção.

Aspecto 4: Concorrência desleal

ADI $[$ [UPF_SO15] Práticas e medidas de combate à concorrência desleal.

Aspecto 5: Conformidade

ADI $[$ [UPF_SO16] Iniciativas, práticas adotadas e medidas mitigatórias adotadas frente aos casos de não-conformidade com leis e regulamentos.

RESPONSABILIDADE PELO PRODUTO

Classe Indicador

Aspecto 1: Saúde e Segurança do cliente

ADI $[$ [UPF_PR10] Medidas adotadas visando à saúde e segurança do cliente.

Aspecto 2: Divulgação dos serviços

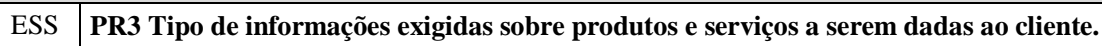

Aspecto 4: Privacidade do cliente

ADI [UPF_PR11] Programas, práticas, iniciativas e medidas adotadas em favor da privacidade do cliente.

Aspecto 5: Conformidade

ADI [UPF_PR12] Descrição dos mecanismos de avaliação (internos e externos) da conformidade de produtos e serviços.

ADI [UPF_PR13] Conceito atribuído ao fornecimento e uso de produtos e serviços.

Fonte: Elaborado pela Autora a partir da GRI versão G3.1 (2011) 
Dentre todas as dimensões (econômica, ambiental e social), nenhum novo aspecto foi apontado para ser incluído nos Conjuntos de Protocolos de Indicadores, fazendo com que permanecessem os mesmos 37 (trinta e sete) aspectos originalmente descritos pela GRI, o que mostra consonância com o perfil de atividade da universidade.

De um total de 84 (oitenta e quatro) indicadores da GRI, 2 (dois) indicadores foram excluídos, ambos pelos gestores, durante as entrevistas (um deles foi excluído pelo gestor da dimensão social, que trata das Práticas Trabalhistas e Trabalho Decente e o outro por ambos os dois gestores da dimensão social, que trata da Responsabilidade pelo Produto). Mostrando que 2,38\% dos indicadores da GRI apresentaram incompatibilidade com as atividades desenvolvidas pela IES.

Do total de 84 (oitenta e quatro) indicadores da GRI, 23 (vinte e três) sofreram alterações, com complementação nas suas descrições ou alteração em suas edições, mostrando que $27 \%$ dos indicadores da GRI necessitaram adequação às atividades da IES. Foram mantidos, da mesma forma como são descritos originalmente pela GRI, 59 (cinquenta e nove) indicadores, mostrando que 70\% dos indicadores se mostraram compatíveis com as atividades da IES (Figura 5).

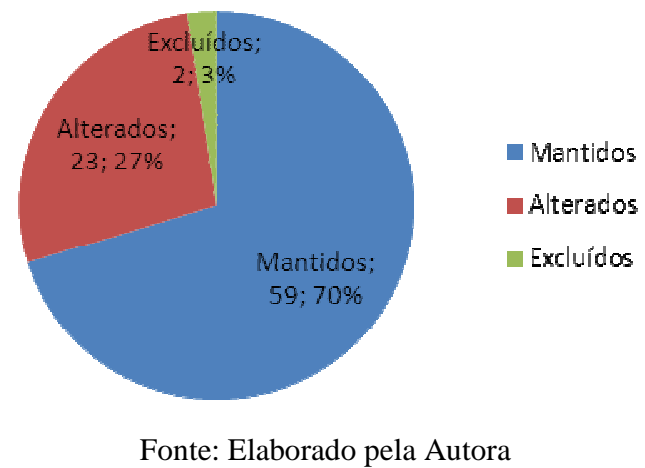

Figura 5 - Proporção do resultado entre indicadores da GRI

Ao findar a triangulação e análise dos dados da pesquisa obteve-se um total de 111 (cento e onze) indicadores, sendo destes 59 (cinquenta e nove) que representam $70 \%$ dos que se mantiveram idênticos aos da GRI, mostrando grande compatibilidade do modelo ao intento do relato da sustentabilidade na IES. Sofreram alterações 23 (vinte e três) indicadores, o que representam $21 \%$ dos que tiveram mudanças em sua edição, descrição ou classe. Foram excluídos 2 (dois) indicadores representaram $2 \%$ de exclusão. Foram incluídos 27 (vinte e sete) indicadores, mostrando que $24 \%$ da estrutura obtida através da pesquisa foi suplementada com indicadores totalmente novos (Figura 6).

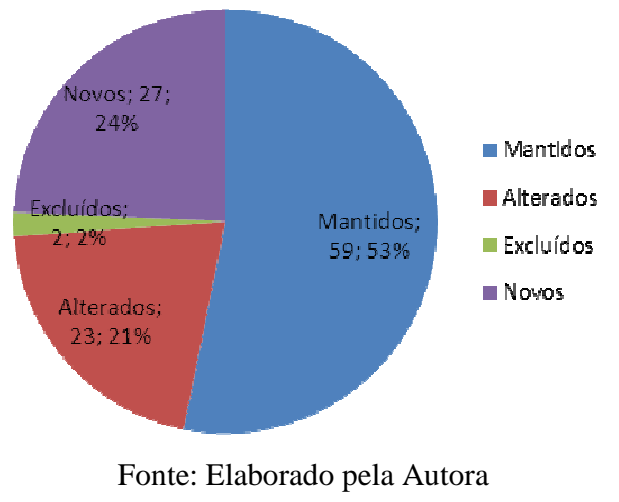

Figura 6 - Proporção de indicadores da estrutura do Relatório de Sustentabilidade da UPF 
Analisando a estrutura de indicadores que se obteve com esta pesquisa, pode-se observar a forte aderência à estrutura original da GRI, evidenciando-a como modelo unânime entre organizações de diversas naturezas. Os aspectos de cada dimensão também se mantiveram análogos aos da GRI. Contudo, as propostas de alterações e adição de novos indicadores evidenciaram a necessidade de ajustes e aporte do modelo da GRI para que se obtenha um relato mais característico ao perfil da IES e capazes de ampliar a transparência no relato do desempenho de sustentabilidade.

No estudo de caso realizado por Trentin (2011), na mesma universidade desta pesquisa, foi analisada a vinculação entre os indicadores da GRI e o Balanço Social IBASE 2009 da instituição. O autor buscou encontrar informações no Balanço Social que possuíssem relação com os indicadores da GRI, ou seja, o que já haveria de informações no documento elaborado pela IES para fazer parte da elaboração de um RS da GRI. O estudo evidencia que poucas informações contidas no Balanço Social IBASE da instituição poderiam responder aos indicadores da GRI. Mostrando que as ações em prol da sustentabilidade ainda se mostram desarticuladas. Tais ações fazem parte do dia a dia da universidade, e aparecem em diferentes atividades e níveis, porém apresentam-se de forma isolada e proveniente das percepções de seus gestores em função de garantir o atendimento a normas, leis e regulamentos.

Esta desconexão também é mostrada no estudo de Termignoni (2012) que argumenta que as pesquisas relacionadas ao desenvolvimento sustentável nas universidades enfocam principalmente a dimensão ambiental, mostrando separação na gestão das dimensões, o que dificulta e se mostra na contramão da perspectiva de uma ampla análise e divulgação da sustentabilidade das universidades, requerendo estudos mais abrangentes.

É relevante apontar que os gestores mostraram ter diferentes entendimentos do conceito de sustentabilidade e carências nos aspectos técnicos, revelando que, assim como suas ações refletem características individuais, suas gestões são passíveis de serem implementadas de forma distinta e não unificada. Todavia, vale ressaltar que, todos trataram como importante a busca contínua da incorporação da sustentabilidade nas suas gestões, e reconheceram que ainda precisam amadurecer e se articular em busca de um modelo que integre ambas as três dimensões.

A inclusão de novos aspectos não foi aderida pelos gestores, assim como também pôde ser evidenciado no estudo realizado por Termignoni (2012) que resultou em um framework de indicadores também para IES comunitárias.

A semelhança entre os estudo se dá por ambos resultarem em indicadores que visam o relato das práticas e campanhas de conscientização dos usuários na economia de água e energia, dos programas de educação ambiental e dos impactos ambientais significativos dos transportes (alunos, funcionários, frota, bens/ materiais). Outro, descrito de forma distinta, porém com o mesmo intuito, é a existência de estruturas e ações voltadas à promoção e difusão cultural, uma vez que a UPF possui diversificadas ações com este fim.

Outros, porém, aparecem exclusivamente no framework de Termignoni, como a descrição da utilização de materiais reciclados e a utilização como matéria-prima de resíduos provenientes de outros processos, e também das construções e reformas das edificações com utilização de critérios ambientais. Outro diferencial está no indicador que busca o relato das empresas contratadas e fornecedores críticos que passam por avaliações com critérios socioambientais para suas contratações em caso de empate de licitações e tomadas de preço.

Comparativamente, a estrutura de indicadores de Termignoni (2012) tem resultado semelhante ao obtido pela pesquisa, já em comparação ao estudo de Madeira (2008), esta pesquisa resultou em poucos indicadores diretamente relacionados às atividades do setor educacional. Na estrutura da autora, na seção suplementar voltada para o setor de educação, aparecem indicadores que caracterizam a comunidade acadêmica onde, relativo aos alunos, está o relato da distribuição dos alunos segundo o 
gênero, a origem geográfica, a idade; percentagem de alunos pertencentes a minorias étnicas e com incapacidades; número de alunos com bolsas e financiamentos educacionais relativamente ao número total de alunos; percentagem de organizações estudantis cuja função se encontra relacionada com a sustentabilidade. Em relação aos funcionários, indicadores que traçam um perfil, acrescidos dos que relatam a proporção de funcionários cujo trabalho se encontra relacionado com a sustentabilidade.

No estudo de Madeira (2008) aparecem indicadores do desenvolvimento de projetos de pesquisa em prol da sustentabilidade, para relatar o valor e a percentagem anual de financiamento de projetos de pesquisa em sustentabilidade em relação ao financiamento total dos projetos de pesquisa e também a percentagem de alunos de pós-graduação que fazem pesquisa em áreas afins à sustentabilidade, por ano e a percentagem de docentes e investigadores que fazem pesquisa na área da sustentabilidade, por ano. Todos estes com a finalidade de revelar grau de envolvimento, o nível de comprometimento e o direcionamento das pesquisas para os assuntos relacionados à sustentabilidade.

Ainda, em relação às publicações, a descrição da percentagem de artigos publicados anualmente em revistas científicas nacionais e internacionais que são relativos a áreas afins à sustentabilidade.

Durante a pesquisa não foram apontados pelos gestores indicadores que se relacionassem ao número, percentual de pesquisas e publicações relacionadas com a sustentabilidade, o que teria grande valia para um melhor encaminhamento das pesquisas conforme as necessidades da sociedade, principalmente da comunidade regional e local.

Há também os indicadores destinados a transparecer a qualidade dos cursos com conteúdos em sustentabilidade, que buscam descrever o número de cursos com conteúdo programático relevante relacionado à sustentabilidade que tenham tido uma boa classificação em avaliações, face ao número total de cursos com boa classificação em avaliações.

Já os indicadores da formação da comunidade acadêmica para a sustentabilidade são igualmente encontrados na estrutura de Madeira (2008).

Observa-se que o foco de cada suplemento de indicadores é bastante distinto em função das particularidades das atividades de cada setor, assim como é evidenciado para o setor de educação através do suplemento obtido com esta pesquisa, onde os 27 (vinte e sete) novos indicadores mostram que $24 \%$ da estrutura obteve a contribuição de indicadores totalmente particulares e característicos ao funcionamento da universidade.

\section{6 - CONCLUSÃO}

Conclui-se que o Relatório de Sustentabilidade da GRI é um instrumento adequado para a divulgação da sustentabilidade da instituição. Os resultados obtidos mostram que está alinhado às questões tratadas, todavia mostrou-se necessário o ajuste e suplementação para que haja uma adequabilidade às atividades desenvolvidas na Instituição de Ensino Superior pesquisada.

Com tal ajustamento a IES pode obter um relato melhor, mais abrangente, característico e assertivo das questões relativas à sustentabilidade.

A estrutura de indicadores, proposta nesta pesquisa, possibilita ainda que a IES a utilize para o desenvolvimento de políticas, planos e ações, levando em conta a sustentabilidade como um todo, abrangendo de forma integral e integrada as dimensões econômica, ambiental e social, e não partindo de ações isoladas e desconexas. 


\section{REFERÊNCIAS BIBLIOGRÁFICAS}

BCSD - Business Council for Sustainable Development. Coletânea Revista Inovação, Tecnologia, Sustentabilidade e Sociedade. Portugal: BCSD-Conselho Empresarial para o Desenvolvimento Sustentável, 2007.

BINKOWSKI, G. Aderir à GRI é um investimento. 2008. Disponível em: <http://www.acionista.com.br/sustentabilidade/150908_GRI_investimentos.htm> Acesso em: jan. 2012.

BLEWITT, John. Good Practice in Sustainable Development Education: Evaluation Report and Good Practice Guide. 2001. Disponível em: <http://www.desd.org.uk/UserFiles/File/new_articles/england/lsda_lsn/LSDA_2002-

Good_practice_in_ESD.pdf> Acesso em: mai. 2012.

CASSOL, Maurício. Uma proposta de balanced scorecard e mapa estratégico para a gestão estratégica de uma instituição de ensino superior privada. Porto Alegre, 2006. 188 f. Dissertação (Mestrado em Administração e Negócios) - PUCRS, Faculdade de Administração, Contabilidade e Economia.

CLARK, B.R. Sustaining Change in Universities: Continuities in Case Studies and Concepts. Tertiary Education and Management. The Netherlands: v. 9, n.2, 2003, p. 99-116.

CMMAD - Comissão Mundial sobre o Meio Ambiente e Desenvolvimento. Nosso Futuro Comum. 2. Ed. Rio de Janeiro: Editora da Fundação Getúlio Vargas, XVIII, 430p. 1991.

CONTO, Suzana. Gestão de resíduos em universidades: uma complexa relação que se estabelece entre heterogeneidade de resíduos, gestão acadêmica e mudanças comportamentais. In: CONTO, Suzana. Gestão de resíduos em universidades. Caxias do Sul: Educs, 2010.

CORDANI, U. G. As Ciências da Terra e a Mundialização das Sociedades. Estudos Avançados, v. 25, p. 13-27, 1995.

CORTESE, A. D. The critical role of Higher Education in creating a sustainable future. Planning for Higher Education. S.N. 2003, p. 15-22.

DYLLICK, T.; HOCKERTS, K. Beyond the business case for corporate sustainability. Business Strategy and the Environment, New York, v. 11, n. 2, p. 130-141, 2002.

ELKINGTON, John. Sustentabilidade, canibais de garfo e faca. São Paulo: M. Books do Brasil Editora Ltda., 2011. 488p.

EVANGELINOS, K. I.; JONES, N.; PANORIOU, E. M. Challenges and opportunities for sustainability in regional universities: a case study in Mytilene, Greece. Journal of Cleaner Production, v. 17, p. 1154-1161, 2009.

FDC - Fundação Dom Cabral. Global Reporting Initiative (GRI). 06 mar 2012. Disponível em: <http://www.fdc.org.br/pt/blog_sustentabilidade/Lists/Postagens/Post.aspx?ID=34\#Comments.> Acesso em: mar. 2012. 
GRI - Global Reporting Initiative. 2012. Disponível em: 〈http://www.globalreporting.org>. Acesso em: jan. 2012.

GUMMESSON, E. Case study research and network theory: birds of a feather. Qualitative Research in Organizations and Management: International Journal, v. 2, n. 3, p. 226-248, 2007.

HARRIS, J. M. Basic Principles of Sustainable Development. G-DAE, 2000. Disponível em: <http://ase.tufts.edu/gdae/publications/working_papers/Sustainable\%20Development.PDF> Acesso em: out. 2011.

ETHOS, Instituto. Relatório de Sustentabilidade GRI. Disponível em: <http://www1.ethos.org.br/EthosWeb/pt/1400/o_instituto_ethos/o_unietho.aspx>. Acesso em: jan. 2012.

KRAEMER, M. E. P. A universidade do século XXI rumo ao desenvolvimento sustentável. Revista Eletrônica de Ciência Administrativa, vol.3, n 2, 2004.

LEGITIMUS, Relações Governamentais e Institucionais. GRI. Disponível em: <http://www.legitimus.com.br/index.php/content/view/265/GRI.html> Acesso em: jan. 2012.

MADEIRA, A.C.F.D. Indicadores de Sustentabilidade para Instituições de Ensino Superior. Dissertação de Mestrado. Faculdade de Engenharia da Universidade do Porto. 2008. 220 pg.

MARTINS, G. A. Estudo de caso: uma reflexão sobre a aplicabilidade em pesquisas no Brasil. Revista de Contabilidade e Organizações, v. 2, n. 2, p. 9-18, jan./abr., 2008.

NICOLADES, A. The implementation of environmental management towards sustainable universities and education for sustainable development as ethical imperative. International Journal of Sustainability in Higher Education, Vol.7, n.4, p. 414-424, 2006.

ROBINSON, S. Key survival issues: practical steps toward corporate environmental sustainability. Corporate Environmental Strategy, New York, v. 7, n. 1, p. 92-105, 2000.

SALGADO, Maria Francisca M. A. Desenvolvimento de programa de gestão ambiental para Instituições de Ensino Superior. Estudo de caso: Instituto Esperança de Ensino Superior. Niterói, 2006. 144 f. Dissertação de Mestrado em Sistemas de Gestão - UFF, Fac. de Administração.

SAVITZ, Andrew W. A empresa sustentável: o verdadeiro sucesso é o lucro com responsabilidade social e ambiental. Rio de Janeiro: Elsevier, 2007.

TAUCHEN, J. A. Um modelo de gestão ambiental para implantação em instituição de ensino superior. Dissertação de mestrado. Programa de Pós-graduação em Engenharia, Faculdade de Engenharia e Arquitetura, Universidade de Passo Fundo. 2007. Disponível em: <http://www.ppgeng.upf.br/images/stories/2005joeltauchen.pdf> Acesso em: jan. 2012.

TERMIGNONI, L. D. F. Framework de sustentabilidade para instituições de ensino superior comunitárias. Porto Alegre, 2012. Dissertação (Mestrado em Administração e Negócios) - Faculdade de Administração, Contabilidade e Economia, Pontifícia Universidade Católica do Rio Grande do Sul, 2012. 
TRENTIN, Adan. A Utilização da GRI na Transformação de um Balanço Social em Relatório de Sustentabilidade: Estudo de Caso Fundação Universidade de Passo Fundo. Monografia (Graduação em Engenharia Ambiental). Faculdade de Engenharia e Arquitetura, Universidade de Passo Fundo. 2011.

ULSF - Association of University Leaders for a Sustainable Future. The Declaration. Vol. 3, No.1, 1999.

UNIVERSIDADE DE PASSO FUNDO. Balanço Social IBASE UPF/2010. 2011a. Disponível em: <http://www.upf.br/fupf/download/balanco_social_2010/balancosocial2010.swf> Acesso em: Abr. 2012.

VAN BELLEN, Hans Michael. Indicadores de sustentabilidade: uma análise comparativa. Florianópolis, 2002. 220p. Tese (Doutorado em Engenharia de Produção) Faculdade de Engenharia (UFSC).

VELAZQUEZ, L.; MUNGUIA, N.; PLATT, A.; TADDEI, J. Sustainable University: what can be the matter? Journal of Cleaner Production, v.14, p. 810-819, 2006.

VELAZQUEZ, L.; MUNGUIA, N.; SANCHEZ, M. Deterring sustainability in higher education institutions. International Journal of Sustainability in Higher Education, v. 6, n. 4, p. 383-391, 2005.

WEENEN, Van H. Towards a vision of a sustainable university. International Journal of Sustainability in Higher Education, v. 1, n. 1, p. 20-34, 2000.

WRIGHT, T. S. A. The Role of Research in Achieving a Sustainable Future? Holmberg, Drivers and Barriers for Implementing Sustainable Development in Higher Education, Goteborg Workshop, 2005, p. 121-25. Disponível em: <http://unesdoc.unesco.org/images/0014/001484/148466E.pdf>. Acesso em: mar. 2012.

YIN, R.K. Estudo de caso: planejamento e métodos. 2. ed. Porto Alegre: Bookman, 2001. 